\title{
Review of the measles epidemic in children from Central Eastern Europe in the third millennium
}

\author{
ANA-MARIA DAVITOIU ${ }^{1,2}$, LUMINITA SPATARIU ${ }^{1,2}$, DOINA-ANCA PLESCA ${ }^{1,2}$, \\ MIHAI DIMITRIU $^{1}$, CATALIN GABRIEL CIRSTOVEANU ${ }^{1,3}$ and SORINA CHINDRIS ${ }^{1,2}$ \\ ${ }^{1}$ Department of Paediatrics, 'Carol Davila' University of Medicine and Pharmacy, 050474 Bucharest; \\ ${ }^{2}$ Department of Paediatrics, 'Dr. Victor Gomoiu' Children Clinical Hospital, 022102 Bucharest; \\ ${ }^{3}$ Neonatal Intensive Care Unit, 'Marie Curie' Emergency Clinical Hospital, 077120 Bucharest, Romania
}

Received March 3, 2021; Accepted April 2, 2021

DOI: $10.3892 / \mathrm{etm} .2021 .10248$

\begin{abstract}
Measles is an extremely contagious viral disease. Even though a safe vaccine exists for this disease, it remains one of the leading causes of mortality and morbidity in infants and young children. We aimed to create a retrospective descriptive study in which to analyze the evolution of the measles epidemic at the European level. The documentation was carried out using European Centre for Disease Prevention and Control (ECDC) and World Health Organization (WHO) statistics. At the same time, we present the epidemic's evolution in Romania, using data provided by the Romanian National Institute of Public Health and Ministry of Health. European statistical data indicate a high number of patients diagnosed with measles both among children and adults. All European countries benefit from the measles vaccination in the form of the measles-mumps-rubella (MMR) trivaccine included in their National Vaccination Programme. The vaccination schedule varies from country to country. In the vaccination scheme, most European countries include two doses of the MMR vaccine among the pediatric population. Romania registered a limited number of cases of measles between 1980 and 2015 following the introduction of the measles vaccination in the National Vaccination Programme. Since 2005, the Romanian vaccination schedule includes two doses of MMR trivaccine, administered at 12 months and at 6-7 years. After 2015 , as a result of a significant decrease in the number of
\end{abstract}

Correspondence to: Dr Catalin Gabriel Cirstoveanu, Neonatal Intensive Care Unit, 'Marie Curie' Emergency Clinical Hospital, Boulevard Constantin Brancoveanu, Nr. 20, Sector 4, 077120 Bucharest, Romania

E-mail: cirstoveanu@yahoo.com

Abbreviations: MMR, measles-mumps-rubella; ECDC, European Centre for Disease Prevention and Control; WHO, World Health Organization; INSP, Romanian National Institute of Public Health

Key words: measles, children, vaccination, Romania, Central-East Europe vaccinated children, Romania is facing a major increase in the cases of measles. Consecutively, a measles epidemic was declared in 2016 and an additional dose of mandatory MMR trivaccine was introduced at the age of 9 months. After 4 years of this schedule of administration, starting with August 2020, the additional dose of MMR administered during infancy has been discontinued. We propose an analysis of the factors that influenced the downward evolution of the measles epidemic in Romania at the beginning of the third millennium. Issues related to the limitation of interpersonal contact in the context of the social distancing imposed by the Sars-CoV-2 virus pandemic are discussed. We consider necessary a detailed documentation of the percentage of new disease cases that will appear in the pediatric population in the near future, in the context of the resumption of daily activity after the reopening of nurseries, kindergartens and schools.

\section{Introduction}

Measles, tuberculosis, influenza, meningococcal disease, whooping cough and tetanus are all infectious diseases for which there is a vaccine. And yet these are diseases that result in a large number of deaths in the third millennium (1).

Measles is an extremely contagious viral disease. It is one of the leading causes of mortality and morbidity in infants and young children despite of the availability and safety of existing vaccines (2).

Measles continues to circulate across Europe as a result of suboptimal vaccination coverage and population immunity gaps (3); Eastern Europe being one of the most affected regions for the incidence of measles (2).

A vaccine is a biological product that contains attenuated pathogens capable of inducing a protective immune response to a particular microbial aggression. The action of the vaccine can be quantified by specific antibodies that appear in the blood of the vaccinated patient (4). Over time, the administration of vaccines has reduced the incidence of a large number of diseases that pose a major threat to health in the European region and thus, vaccines have saved millions of lives.

In Central and Eastern Europe, in the totalitarian context imposed by the communist regimes, the vaccination schemes were rigorously structured and administered to the 
pediatric population for the entire time of the communist regime (5). As a result, there appears to be a low incidence of vaccine-controlled infectious diseases at that time.

\section{Materials and methods}

We aim to create a retrospective descriptive study in which to analyze the evolution of the measles epidemic at the European level. The documentation was carried out using European Centre for Disease Prevention and Control (ECDC) and World Health Organization (WHO) statistics from 2005 to 2020 . At the same time, we present the epidemic's evolution in Romania, using data provided by the Romanian National Institute of Public Health and Ministry of Health.

The schemes of the national vaccination program at the level of European countries were analyzed retrospectively. An attempt was made to establish correlations between vaccine coverage at the state level and the number of measles-mumps-rubella (MMR) vaccine doses in the National Vaccination Programme, respectively the number of new cases of measles per 1,000 inhabitants.

In Romania, we analyzed the evolution of the measles cases during the communist regime compared with the number of cases after 1990, in the context of the decrease in vaccine coverage. We aimed to identify the cause of the increase in the percentage of cases in relation to the decrease in the percentage of vaccination in the pediatric population.

The article goes into detail with regard to the statistical differences between the number of cases of measles in children and adults before 2016, when the measles epidemic was declared, and the number of cases subsequent to the decline generated by the changes brought to the national programme in terms of measles vaccination. The new vaccination schedule is presented. This one involves the administration of 2 doses of MMR trivaccine in the first year of life and one dose of booster vaccine at the age of 5 years. The decrease in the disease incidence during 2016-2020 is statistically demonstrated.

\section{Results and Discussion}

Measles epidemic in Europe. The measles epidemic between 2010-2020 in Europe is reflected in the large number of measles cases that spread across the continent (6) (Fig. 1).

The national vaccination schedule differs from country to country both in the epidemic time and the current period. It should be noted that, for most countries, according to ECDC, the national vaccination schedule includes two doses of measles vaccine from the MMR trivaccine (2).

A coverage of vaccination over $95 \%$ with two doses of measles vaccine is crucial to achieve, in order to eliminate the disease throughout Europe (2). The vaccine coverage rate in Europe with two doses of measles vaccine is estimated at only $90 \%$ by 2018 . As a result, in 2018 in Europe, 83,540 cases of measles were reported; almost four times more than in 2017 (25,870 cases) (7).

Measles-related mortality is most often due to complications of the disease such as pneumonia or encephalitis and less to the disease itself (8). In 2019, the death rate per 1,000 cases was 0.89 . The numbers may be higher if we take into account the deaths related to the complications of the disease (7). In addition, subacute sclerosing panencephalitis is a rare and invariably fatal complication of the disease. This complication develops years after the occurrence of the acute measles episode and it increases the measles mortality rate (9).

The data provided by ECDC concerning Central and Eastern Europe show significant variations from one country to another. Between March 2019 and February 2020, the number of measles cases in the analyzed countries had an overall downward evolution. Exceptions to this situation include Romania and Bulgaria which continued to present an increased number of cases in the first two months of 2020 (10) (Table I).

The monthly measles and rubella monitoring report April 2020 of ECDC presented data concerning the incidence of measles in the $29 \mathrm{EU} / \mathrm{EEA}$ member states, including the UK. It reported 11,576 cases of measles for the interval March 1, 2019 to February 29, 2020 (2). No country had zero cases during that period. France ranked first (2,466 cases) followed by Romania (1,542 cases), Italy (1,353 cases) and Bulgaria (1,347 cases). During the mentioned period, 8 deaths were reported (25\% of deaths being registered in Romania) (2).

Particularities of the measles epidemic in Romania. Over time, after the introduction of the measles vaccination in 1979, measles still produced several epidemics in Romania (in 1982, 1986, 1993, 1997, 2003, 2010 and 2016) but with new cases and the number of deaths lower than were registered in the prevaccination period (11). According to the data provided by the National Institute of Public Health, the D4 genotype of measles virus is endemic in Romania (11). In the context of the democratic approach of the last decade of the 20th century which associated a free movement of the population on the background of open border circulation, two other genotypes of measles virus, B3 and D8, considered imported genotypes were identified in Romania $(11,12)$.

Information provided by ECDC between February 1, 2016 and January 31, 2017, shows that eight European countries (Austria, Czech Republic, France, Germany, Ireland, Italy, Spain, UK) reported 34 confirmed cases of measles (12). Based on the circulated genotypes, ECDC supports the possibility that their origin was from Romania (13).

Statistical data from Romania indicate that during the 1960-1980 period, the measles incidence remained high at about 120 new cases per 100,000 population. After the introduction of the measles vaccination in 1979, there was a dramatic decrease in these numbers, below 40 new measles cases per 100,000 population (11) (Fig. 2).

In Romania, the vaccination schedule was modified since 2005 by introducing in the National Vaccination Program the measles-rubella-mumps (MRM) trivaccine which is administered at the age of 12 months with a booster at the age of 6-7 years. Vaccine coverage was maintained at over $95 \%$, the WHO target (14). As a result, the incidence of the disease continued to remain low from 2005 to 2015.

After 2015, the incidence of measles in pediatric patients increased alarmingly (11). Researchers correlate this with a significant reduction in the percentage of infants and young 


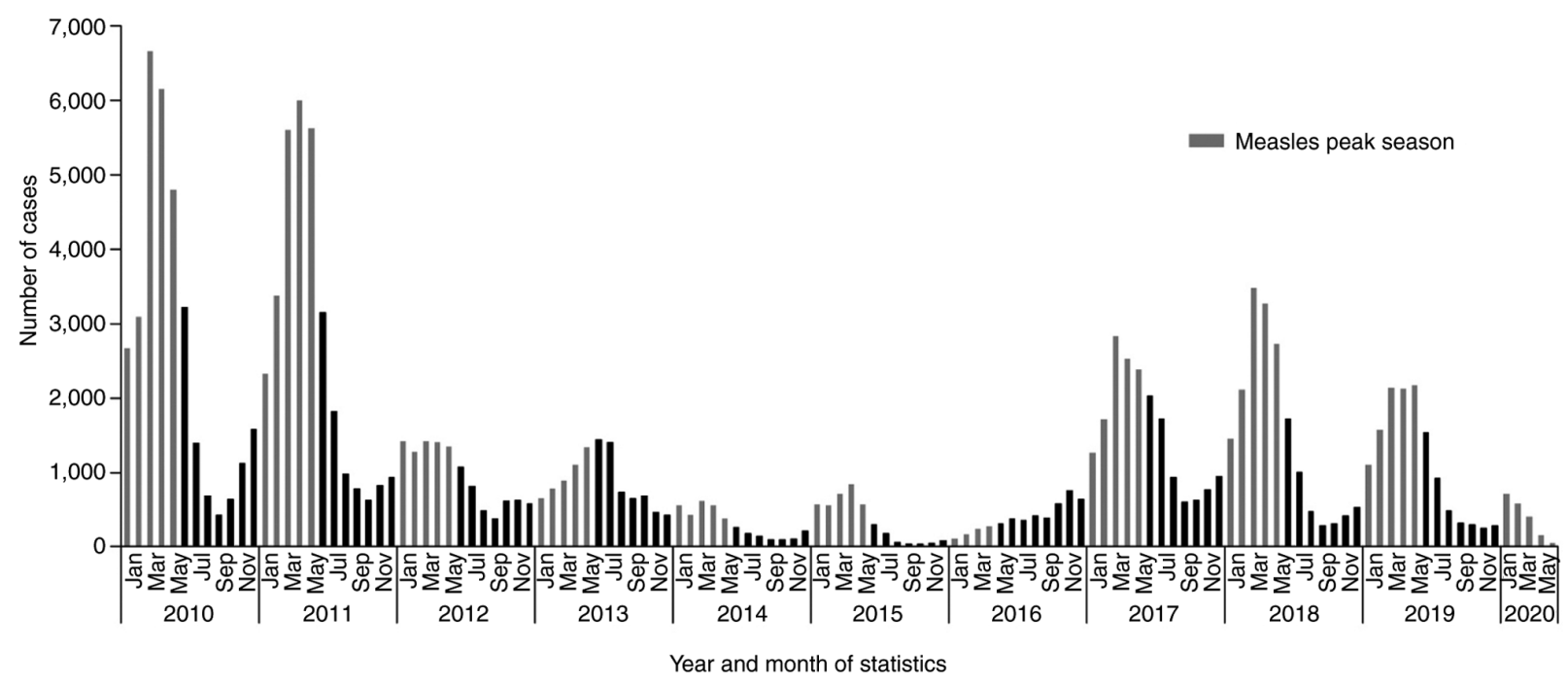

Figure 1. Measles cases (possible, probable, confirmed) between January 2010 and May 2020, reported by month and year in EU/EEA and the UK (source TESSy)-adapted from European Centre for Disease Prevention and Control (5). EU/EEA, European Union/European Economic Area.

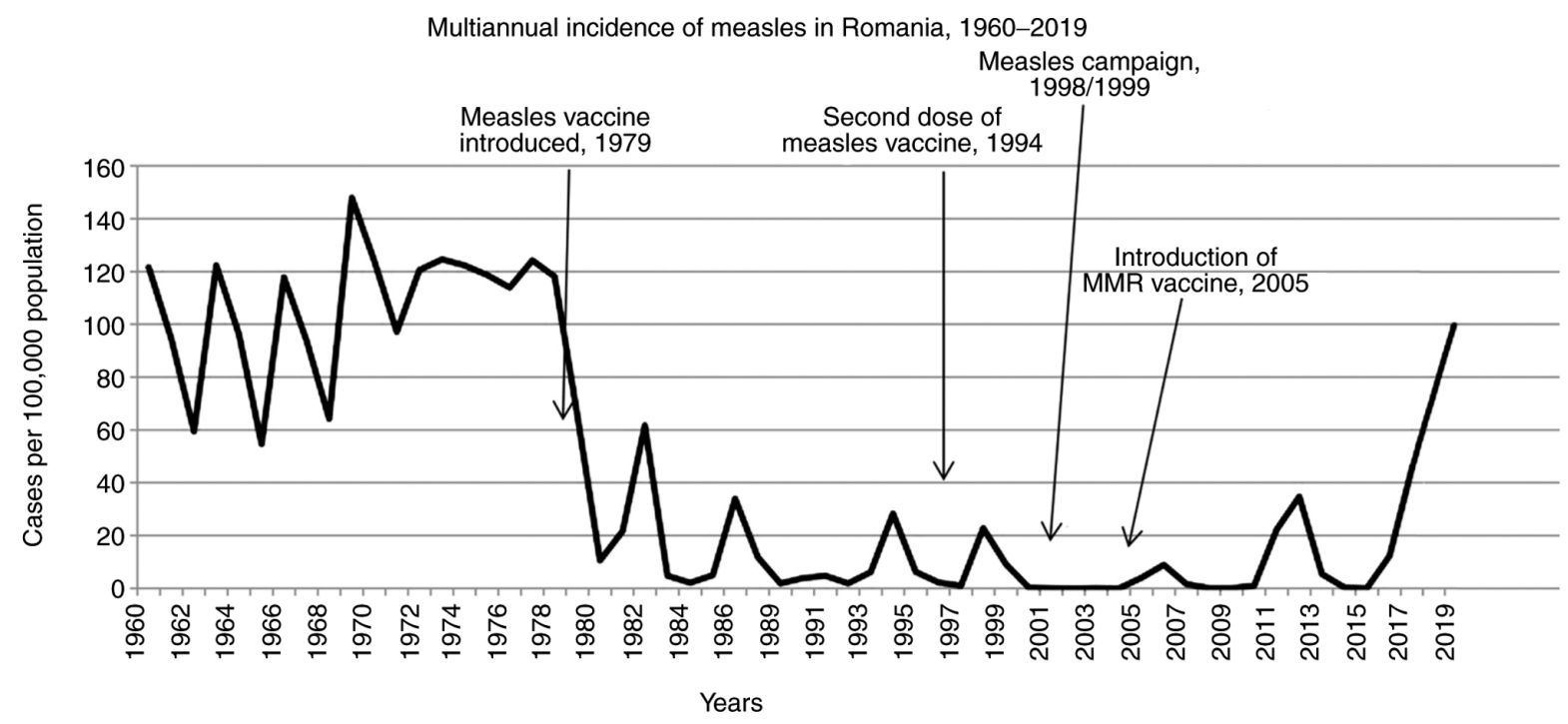

Figure 2. Multiannual incidence of measles in Romania between January 1960 and July 2020. Adapted from Romanian National Institute of Public Health (9).

children vaccinated against measles secondary to a misunderstood democracy consisting in vaccine delays and refusals of vaccination (15). In addition, media coverage of Dr Andrew Wakefield's publications, established a false correlation between MMR vaccination and autism, an idea which is widely reported among parents (16). Consecutively, this resulted in a decreased trend of vaccine coverage. In 2018, only $90 \%$ of the pediatric population from Romania was covered by MMR vaccination at the age of 12 months (17).

The distribution of measles cases among the pediatric population of Romania between 2005-2019 is shown in Tables II and III based on data collected from ECDC and INSP.

Furthermore, Romania registered in 2016 a worrying number of measles cases in both children and young adults. The Romanian National Institute of Public Health stated that the most affected were children under 1 year, with 723 new cases $/ 100,000$ population, followed by the age group 1-4 years,
3 times lower, and then the incidence declined for the age group 5-9 years to $108 / 100,000$ population and was 35.3/1,000,000 for the age group 15-19 years (11). Thus, in September 2016, a measles epidemic was declared in Romania. Afterwards, for the next two years, the trend continued to be high for the $0-4$ age group as is shown in Fig. 3.

Data from the ECDC showed that in the period of January-December 2020 in Romania there were 1,004 new cases of measles among the population (17). According to INSP $85.74 \%$ of cases were in the age group $0-19$ years. No deaths were reported (18).

The current measles epidemic in Romania has particularly affected children under 1 year old who were not eligible for MMR vaccination according to the Romanian National Program of Vaccination from that time. Starting with December 2016, the Ministry of Health and National Institute of Public Health established the obligation to administer two doses of MMR trivaccine in the first year of life, at the ages 
Table I. Number of cases of measles in Central and Eastern Europe between March 1, 2019 and February 29, 2020 reported monthly and per million population by country (adapted from ECDC).

\begin{tabular}{|c|c|c|c|c|c|c|c|c|c|c|c|c|c|c|}
\hline \multirow[b]{3}{*}{ Country } & \multicolumn{14}{|c|}{ Year } \\
\hline & \multicolumn{14}{|c|}{ Month } \\
\hline & $\begin{array}{l}2019 \\
\text { Mar }\end{array}$ & $\begin{array}{c}2019 \\
\text { Apr }\end{array}$ & $\begin{array}{l}2019 \\
\text { May }\end{array}$ & $\begin{array}{c}2019 \\
\text { Jun }\end{array}$ & $\begin{array}{c}2019 \\
\text { July }\end{array}$ & $\begin{array}{l}2019 \\
\text { Aug }\end{array}$ & $\begin{array}{l}2019 \\
\text { Sept }\end{array}$ & $\begin{array}{c}2019 \\
\text { Oct }\end{array}$ & $\begin{array}{l}2019 \\
\text { Nov }\end{array}$ & $\begin{array}{c}2019 \\
\text { Dec }\end{array}$ & $\begin{array}{c}2020 \\
\text { Jan }\end{array}$ & $\begin{array}{c}2020 \\
\text { Feb }\end{array}$ & $\begin{array}{l}\text { Total } \\
\text { cases }\end{array}$ & $\begin{array}{c}\text { Cases } \\
\text { per million }\end{array}$ \\
\hline Romania & 188 & 110 & 148 & 123 & 110 & 80 & 112 & 100 & 79 & 90 & 257 & 145 & 1,542 & 79.4 \\
\hline Bulgaria & 185 & 279 & 281 & 236 & 84 & 42 & 17 & 5 & 21 & 34 & 81 & 82 & 1,347 & 192.4 \\
\hline Croatia & 0 & 0 & 6 & 4 & 10 & 4 & 14 & 12 & 1 & 0 & 0 & 0 & 51 & 12.5 \\
\hline Cyprus & 0 & 1 & 3 & 1 & 0 & 0 & 0 & 0 & 0 & 0 & 0 & 0 & 5 & 5.7 \\
\hline Czechia & 198 & 90 & 49 & 20 & 14 & 4 & 2 & 1 & 4 & 0 & 0 & 3 & 385 & 36.1 \\
\hline Estonia & 2 & 0 & 6 & 7 & 1 & 1 & 0 & 0 & 0 & 1 & 0 & 0 & 18 & 13.6 \\
\hline Greece & 7 & 12 & 6 & 0 & 0 & 0 & 12 & 3 & 1 & 1 & 1 & 0 & 43 & 4 \\
\hline Hungary & 4 & 2 & 9 & 0 & 1 & 0 & 0 & 0 & 0 & 0 & 0 & 0 & 16 & 1.6 \\
\hline Latvia & 0 & 1 & 0 & 0 & 0 & 2 & 0 & 0 & 0 & 0 & 0 & 0 & 3 & 1.6 \\
\hline Lithuania & 249 & 231 & 125 & 62 & 33 & 39 & 6 & 2 & 2 & 0 & 1 & 0 & 750 & 268.4 \\
\hline Poland & 287 & 289 & 249 & 124 & 41 & 9 & 5 & 6 & 2 & 8 & 5 & 7 & 1,032 & 27.2 \\
\hline Slovakia & 70 & 105 & 43 & 9 & 3 & 6 & 3 & 0 & 0 & 0 & 0 & 0 & 239 & 43.9 \\
\hline Slovenia & 0 & 6 & 8 & 3 & 1 & 1 & 0 & 0 & 7 & 22 & 5 & 1 & 54 & 25.9 \\
\hline
\end{tabular}

ECDC, European Centre for Disease Prevention and Control.

Table II. Distribution of measles cases among the pediatric population of Romania between 2005-2019 (adapted from ECDC).

\begin{tabular}{llllllllllllllll}
\hline Year & 2005 & 2006 & 2007 & 2008 & 2009 & 2010 & 2011 & 2012 & 2013 & 2014 & 2015 & 2016 & 2017 & 2018 & 2019 \\
\hline Cases & 5,647 & 3,196 & 352 & 14 & 8 & 188 & 4,165 & 6,166 & 1159 & 59 & 7 & 1,780 & 7,326 & 4,477 & 2,718 \\
\hline
\end{tabular}

ECDC, European Centre for Disease Prevention and Control.

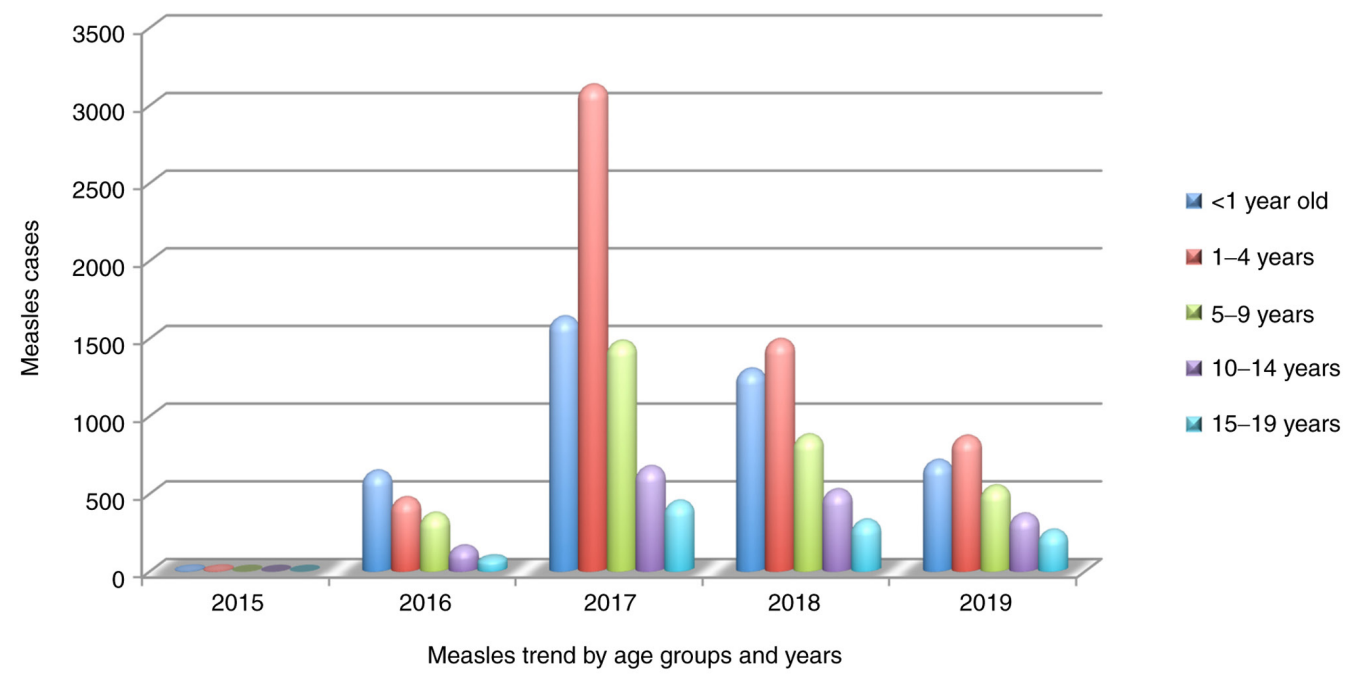

Figure 3. Evolution of cases of measles in Romania by age group between January 2015 and December 2019. Adapted from ECDC and INSP (9). ECDC, European Centre for Disease Prevention and Control; INSP, Romanian National Institute of Public Health.

of 9 and 12 months. The booster dose is maintained at the age of five. Romania is the only country in Central and Eastern
Europe that administers 3 doses of MMR in children, 2 of which are during infancy. 
Table III. Distribution of the cases of measles according to age group in the pediatric population of Romania between 2015 and 2019 (according to INSP).

Age groups (0-19 years of age)

\begin{tabular}{lrrrrrr}
\cline { 2 - 6 } Cases of measles & $<1$ year & $1-4$ years & $5-9$ years & $10-14$ years & $15-19$ years & Total cases \\
\hline 2015 & 3 & 4 & 0 & 0 & 0 & 7 \\
2016 & 336 & 842 & 364 & 152 & 86 & 1,780 \\
2017 & 1,628 & 3,121 & 1,471 & 664 & 442 & 7,326 \\
2018 & 1,292 & 1,482 & 868 & 515 & 320 & 4,477 \\
2019 & 704 & 860 & 540 & 359 & 255 & 2,718 \\
Total cases & 3,963 & 6,309 & 3,243 & 1,690 & 1,103 & 16,308 \\
\hline
\end{tabular}

INSP, Romanian National Institute of Public Health.

During the years preceding the onset of the measles outbreak in Romania, the number of deaths caused by infections with the measles virus was incomparably lower: 2004-2007, 23 deaths; 2010-2013, 4 deaths. The number of deaths increased considerably between 2016 and 2019 reaching 64 deaths out of 18,908 diagnosed cases (11) as is shown in Table IV.

The study of Lazar et al, INSP (unpublished data), showed that between January 2016 and July 2018, 14,825 patients infected with the measles virus were diagnosed in Romania. Most of them were unvaccinated patients, 14,113 (95.2\%). Pediatric patients, infants and children under 5 years of age, accounted for $56 \%$ of the group $(8,259)$.

In 2018, 23 deaths were registered in Romania out of the 74 measles-related deaths in 10 European countries. The mortality rate per 1,000 cases of measles remains at 0.89 . Most of the deaths, $60 \%$ of them, occurred in children under the age of 10 and $2 / 3$ of them have been registered at less than 1 year old (7).

As a result of the changes brought by the Romanian National Vaccination Programme in December 2016 and the concerted efforts of the Romanian medical staff, the number of measles cases in pediatric patients was reduced. The number of measles deaths has also been reduced. The dynamics of the data collected by INSP from May 2019 to May 2020 about the evolution of the measles epidemic shows a downward trend.

The data provided by the study of Pistol et al, INSP (data not published), concerning the National Electronic Vaccination Registry are summarized in Table $\mathrm{V}$ and indicate the vaccination rates with 3 doses of MMR during January-July 2020 in Romania. The data show a vaccination rate between $40-50 \%$ among infants except for April 2020 when the recent pandemic with the Sars-CoV-2 virus was declared on the Romanian territory, and possibly the measures taken during that month decreased the level of vaccinations for a short period.

Thus according to INSP, the incidence of measles at the national level in 2020 was only 5.1/100.000 inhabitants, approximately 4 times lower than in 2019. In the last 6 months, 17 districts out of the 41 districts of Romania have not reported confirmed measles cases. In addition, no measles deaths were reported between December 2019 and November 2020 (18).

In this context, the authorities have decided to discontinue the dose of MMR vaccine administered to infants at 9 months
Table IV. Distribution of the confirmed cases of measles and deaths in Romania between 2016 and 2020 (according to INSP).

\begin{tabular}{lrrrrr}
\hline & \multicolumn{5}{c}{ Year } \\
\cline { 2 - 6 } Measles & 2016 & 2017 & 2018 & 2019 & Total \\
\hline Cases & 1,969 & 8,299 & 5,319 & 3,321 & 18,908 \\
Deaths & 9 & 27 & 23 & 5 & 64 \\
\hline
\end{tabular}

INSP, Romanian National Institute of Public Health.

Table V. MMR vaccination rate among the pediatric population between January and July 2020 (according to INSP).

\begin{tabular}{lccc}
\hline & \multicolumn{3}{c}{ MMR } \\
\cline { 2 - 4 } Month for year 2020 & 9 9-11 months & 12 months & 5 years \\
\hline January & 44.1 & 49.4 & 24.7 \\
February & 42 & 47.1 & 22 \\
March & 38.8 & 47.6 & 20.8 \\
April & 28.1 & 31.8 & 12.1 \\
May & 47 & 51.4 & 27.2 \\
June & 46.1 & 52.5 & 24.8 \\
July & 41.1 & 51.1 & 25.2 \\
\hline
\end{tabular}

MMR, measles-mumps-rubella; INSP, Romanian National Institute of Public Health.

of life returning to the vaccination schedule with two doses of MMR (at the age of 1 year and booster at 5 years). This decision was applied starting from August 1, 2020.

We argue the importance of rigorous surveillance in the next period for new measles cases in both children and adults. The new incidence of the disease will decide if these recommendations were correct. If a large number of newly confirmed cases of measles disease appear, the authorities will consider resuming the vaccination schedule with the administration of 
two doses of MMR at 9 and 12 months and a booster at the age of 5 years.

We take into consideration the possibility of an apparent decline of the disease in the last 4 months in the context of the Sars-CoV-2 virus epidemic in Romania (19). In the context of the pandemic, Romania was in the period of March-May 2020 under the incidence of the emergency state and later, from May to August 2020, under the incidence of the alert state (20). The recommendations for social distancing from this period led to the limitation of the infectious contact between people (21). We consider that indirectly this may have led to a decrease in the measles incidence in Romania.

In conclusion, vaccination is the most effective protection against measles disease and immunization in childhood is the safest start to our road in life.

The measles epidemic appeared in Romania secondary to a decline in vaccine coverage, a phenomenon that was mitigated by adaptive measures that included the development of a vaccination schedule with 3 doses of MMR vaccines which means the introduction of an additional dose at the age of 9 months, with the administration of the following doses at the age of 12 months and 5 years.

The national campaign to limit the measles epidemic had the desired effect. The decrease in the incidence of measles cases among the pediatric population of Romania allowed the authorities to discontinue the MMR vaccine dose administered during the infant period at 9 months starting with August 2020.

We sought to evaluate the decision of the Ministry of Health to discontinue the administration of an additional dose of MMR vaccine during infancy. Early detection of epidemiological signals is important in order to prevent a new measles epidemic. Thus, it is necessary to dynamically monitor new disease cases that will appear on the Romanian territory. Interdisciplinary monitoring of the pediatric patient will detect an increase in the incidence of measles. Consecutively, the second dose of vaccination during infancy may have to be reintroduced.

We point out the possibility of an artificial decrease in the number of measles diseases from January to July 2020 in the context of the social distancing imposed by the Sars-CoV-2 pandemic.

\section{Acknowledgements}

Not applicable.

\section{Funding}

No funding was received.

\section{Availability of data and materials}

The datasets used and/or analyzed during the current study are available from the corresponding author on reasonable request.

\section{Authors' contributions}

AMD conceived of the presented idea. SC developed the theory and performed the computations. LS verified the analytical methods. DAP supervised the literature review and data used. MD was involved in drafting the manuscript and revising it critically for important intellectual content in light of the literature data. CGC also analyzed the data provided and gave final approval of the version to be published, investigate the aspects of the data and supervised the findings of this work. All authors discussed the results and contributed to the final version of the manuscript. All authors read and approved the manuscript and agree to be accountable for all aspects of the research.

\section{Ethics approval and consent to participate}

Not applicable.

\section{Patient consent for publication}

Not applicable.

\section{Competing interests}

No competing interests exist with regard to the publication of the descriptive study.

\section{References}

1. World Health Organization: Immunization, Vaccines and Biologicals on Measles, 2020. Available from: https://www.who. int/immunization/diseases/measles/en/.

2. European Centre for Disease Prevention and Control: ECDC. Monthly measles and rubella monitoring report, 2020. Available from: https://www.ecdc.europa.eu/sites/default/files/documents/measles-rubella-monthly-report-april-2020.pdf.

3. Williams GA, Bacci S, Shadwick R, Tillmann T, Rechel B, Noori T, Suk JE, Odone A, Ingleby JD, Mladovsky P and Mckee M: Measles among migrants in the European Union and the European economic area. Scand J Public Health 44: 6-13, 2016.

4. Guglielmi G: Measles erases immune 'memory' for other diseases. Nature: Oct 31, 2019 (Epub ahead of print). doi: 10.1038/ d41586-019-03324-7.

5. Paul KT and Loer K: Contemporary vaccination policy in the European Union: Tensions and dilemmas. J Public Health Policy 40: 166-179, 2019.

6. Nicolay N, Mirinaviciute G, Mollet T, Celentano LP and Bacci S: Epidemiology of measles during the COVID-19 pandemic, a description of the surveillance data, 29 EU/EEA countries and the United Kingdom, January to May 2020. Euro Surveill 25: 2001390, 2020 .

7. European Centre for Disease Prevention and Control: ECDC. Monthly measles and rubella monitoring report, 2020. Available from: https://www.ecdc.europa.eu/en/rubella/surveillance-and-disease-data/monthly-measles-rubella-monitoring-reports.

8. World Health Organization: WHO EpiBrief. A report on the epidemiology of selected vaccine-preventable diseases in the European region, 2020. Available from: https://www.euro.who. int/_data/assets/pdf_file/0006/431745/EpiBrief_1_2020_EN.pdf.

9. Dayan GH and McLean HQ: Measles: International Encyclopedia of Public Health. 2nd edition. Quah SR (ed), Academic Press, pp565-569, 2017.

10. Ferren M, Horvat B and Mathieu C: Measles encephalitis: Towards new therapeutics. Viruses 11: 1017, 2019.

11. Lazar M, Stănescu A, Penedos AR and Pistol A: Characterisation of measles after the introduction of the combined measles-mumpsrubella (MMR) vaccine in 2004 with focus on the laboratory data, 2016 to 2019 outbreak, Romania. Euro Surveill 24: 1900041,2019.

12. Dascalu S: Measles epidemics in Romania: Lessons for public health and future policy. Front Public Health 7: 98, 2019.

13. Gindrovel D, Alexiu SA, Pistol A and Stănescu A: What have we learnt from the measles outbreak? Medic Ro 2, 2017.

14. Hayman DTS: Measles vaccination in an increasingly immunized and developed world. Hum Vaccin Immunother 15: 28-33, 2019. 
15. Donadel M, Stanescu A, Pistol A, Stewart B, Butu C, Jankovic D, Paunescu B and Zimmerman L: Risk factors for measles deaths among children during a nationwide measles outbreak-Romania, 2016-2018. BMC Infect Dis 21: 279, 2021.

16. Rao TS and Andrade C: The MMR vaccine and autism: Sensation, refutation, retraction, and fraud. Indian J Psychiatry 53: 95-96, 2011.

17. European Centre for Disease Prevention and Control: Number of measles casesby month and notification rate per million population by country, January 2020-December 2020, 2021. Available from: https://www.ecdc.europa.eu/en/publications-data/number-measlescases-month-and-notification-rate-million-population-country-27.

18. European Centre for Disease Prevention and Control: ECDC Number of measles deaths by country, EU/EEA and the UK, December 2019-November 2020, 2021. Available from: https://www.ecdc.europa.eu/en/publications-data/number-measlesdeaths-country-eueea-and-uk-december-2019-november-2020.
19. Stoian AP, Pricop-Jeckstadt M, Pana A, Ileanu BV, Schitea R, Geanta M, Catrinoiu D, Suceveanu AI, Serafinceanu C, Pituru S, et al: Death by SARS-CoV 2-a Romanian COVID-19 multi-center comorbidity study. Res Square 2: 1-21, 2020.

20. Ceriello A, Stoian AP and Rizzo M: COVID-19 and diabetes management: What should be considered? Diabetes Res Clin Pract 163: 108151, 2020.

21. Serban D, Smarandache AM, Cristian D, Tudor C, Duta L and Dascalu AM: Medical errors and patient safety culture-shifting the healthcare paradigm in Romanian hospitals. Rom J Leg Med 28: 195-201, 2020.

This work is licensed under a Creative Commons Attribution-NonCommercial-NoDerivatives 4.0 International (CC BY-NC-ND 4.0) License. 